\title{
Do the New Exchange Rate Indexes Offer Better Answers to Old Questions?
}

\author{
Dallas S. Batten and MichaeI T. Belongia
}

$\mathbf{T}$

HE persistent U.S. trade and current account deficits appear somewhat paradoxical in light of the dramatic decline of the dollar's foreign exchange value against the currencies of industrialized countries since early 1985 . Some analysts have argued that the dollar's decline has been overstated. The traditional dollar exchange rate indexes, which include primarily industrial countries currencies, have been criticized as too narrow to reflect the movement of the dollar accurately. In response to this argument, new, more inclusive aggregate exchange rate measures have been developed.' The new broader indexes are alleged to be better measures of the dollar's foreign exchange value and hence, they should better explain U.S. trade flows.

Although the notion that indexes with a broader range of currencies will contain more information has intuitive appeal, neither economic nor index number theory can be used to determine whether a particular exchange rate index is superior to another. In this article we assess the performance of the new indexes empirically. Specifically, we investigate whether one or more of the new indexes is related more closely to U.S. merchandise exports and U.S. non-petroleum imports than three more established and more traditional exchange rate measures. The performance of

Dallas S. Batten, a former research officer at the Federal Reserve Bank of St. Louis, is currenty deputy assistant secretany for policy coordination at the U.S. Department of the Treasury, and Michael T. Belongia is a senior economist at the Federal Reserve Bank of St. Louis. Anne $M$. Grubish provided research assistance.

'See Cox (1986), Rosensweig (1986). Hervey and Strauss (1987) and Morgan Guaranty (1986). Rosensweig's index is nominat, not real, as this analysis requires. Hence, it is not included in the empirical investigation.

In fact, contrary to the intuitive argument, Belongia (1986) found that centain indexes especially designed for specific purposes performed poorly in their designed role relative to other, more general indexes. the alternative exchange rate indexes is evaluated in terms of their in-sample and out-of-sample statistics.

\section{THE CONSTRUCTION OF EXCHANGE RATE INDEXES}

Constructing a multilateral exchange rate index requires addressing a number of theoretical and statistical issues." The primary issue in this paper is whether the number of currencies in the index matters - a question for which theory offers no guidance. An index also requires a base year for the trade (or other) weights that will be applied to the constituent currencies. It generally is not possible, however, to find a year that satisfies the necessary criteria. ${ }^{4}$ Other practical problems associated with constructing an exchange rate index include the choice of weighting schemes (multilateral or bilateral) and alternative mathematical formulas (geometric or arithmetic). ${ }^{5}$

\section{Characteristics of the Traditional Indeges}

Among the best-known exchange rate indexes are those produced by the Federal Reserve Board (FRB), Morgan Guaranty (MG-15) and the International Mon-

${ }^{3}$ See Dutton and Grennes (1985) for a detailed discussion of theoretical and statistical issues concerning the construction of exchange rate indexes.

in theory, absolute purchasing power parity should hold in the base year and the constituent countries should consume identical commodity bundies. Absolute purchasing power requires an exchange rate that equates the price levels between nations.

sSee Dutton and Grennes (1985), pp. 20-27. Also, see Belongia (1986), p. 7, for a numerical example and further discussion of the distinction between arithmetic and geometric weights. 


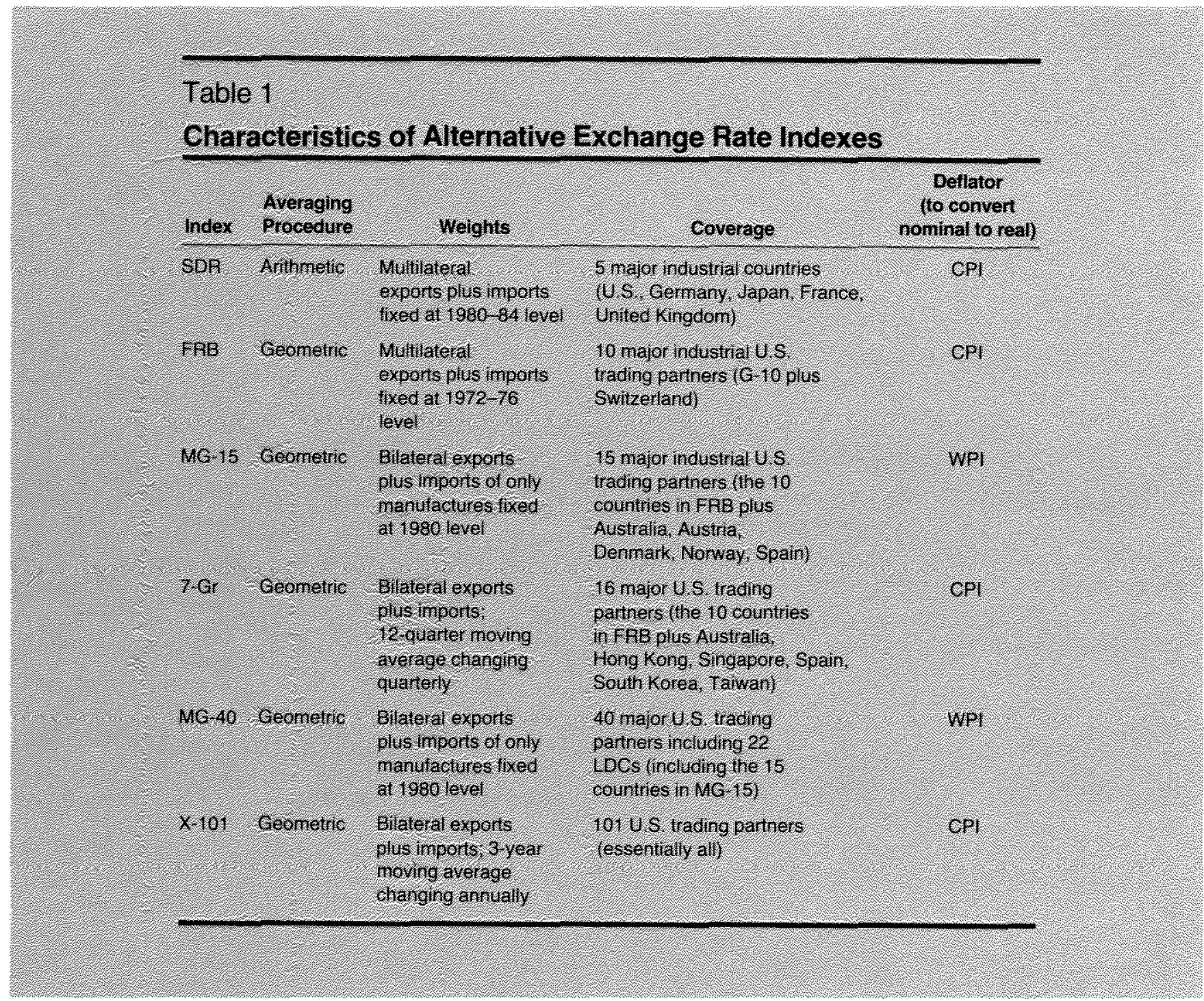

etary fund for the Special Drawing Right (SDR). Their basic characteristics, along with those for the newer indexes - the Federal Reserve Bank of Chicago's 7-Gr, Morgan Guaranty's 40-currency index $(\mathrm{MG}-40$ ), and the federal Reserve Bank of Dallas' X-101 - which will be discussed later, are presented in table 1 . Table 2 reports the weights that each of these indexes assigns to different foreign currencies. The narrowest index is the SDP index, which assigns weights based on the four other currencies (besides the U.S. dollar) that make up the SDR."

'The SDR is the International Monetary Fund's official unit of account and serves as an international reserve asset often used in place of gold for making international payments. Since the SDR is denominated in terms of only the U.S. and four other nations' currencies, however, a doflar exchange rate based on SDR weights reflects changes in the dolar against only four other currencies.
The FRB and MG-15 indexes base their weights primarily on trade with the $\mathrm{G}-10$ countries and Switzerland: These indexes reflect trade among developed, industrialized economies but do not include the currencies of less-developed countries (LDCs). The MG15 index is somewhat more broadly based than the qRB index in that it includes Australia, Spain and several other countries.

The difficulty of choosing among the traditional exchange rate measures to represent the dollar's value is perhaps best illustrated by the relationships in chart

The Group of Ten, or G-10, countries are Belgium, Canada, France, West Germany, Italy, Japan, the Netheriands, Sweden, the United Kingdom and the United States.

${ }^{3}$ A less-developed country typically is defined as one in which per capita income is less than one-fifth of U.S. per capita income. 


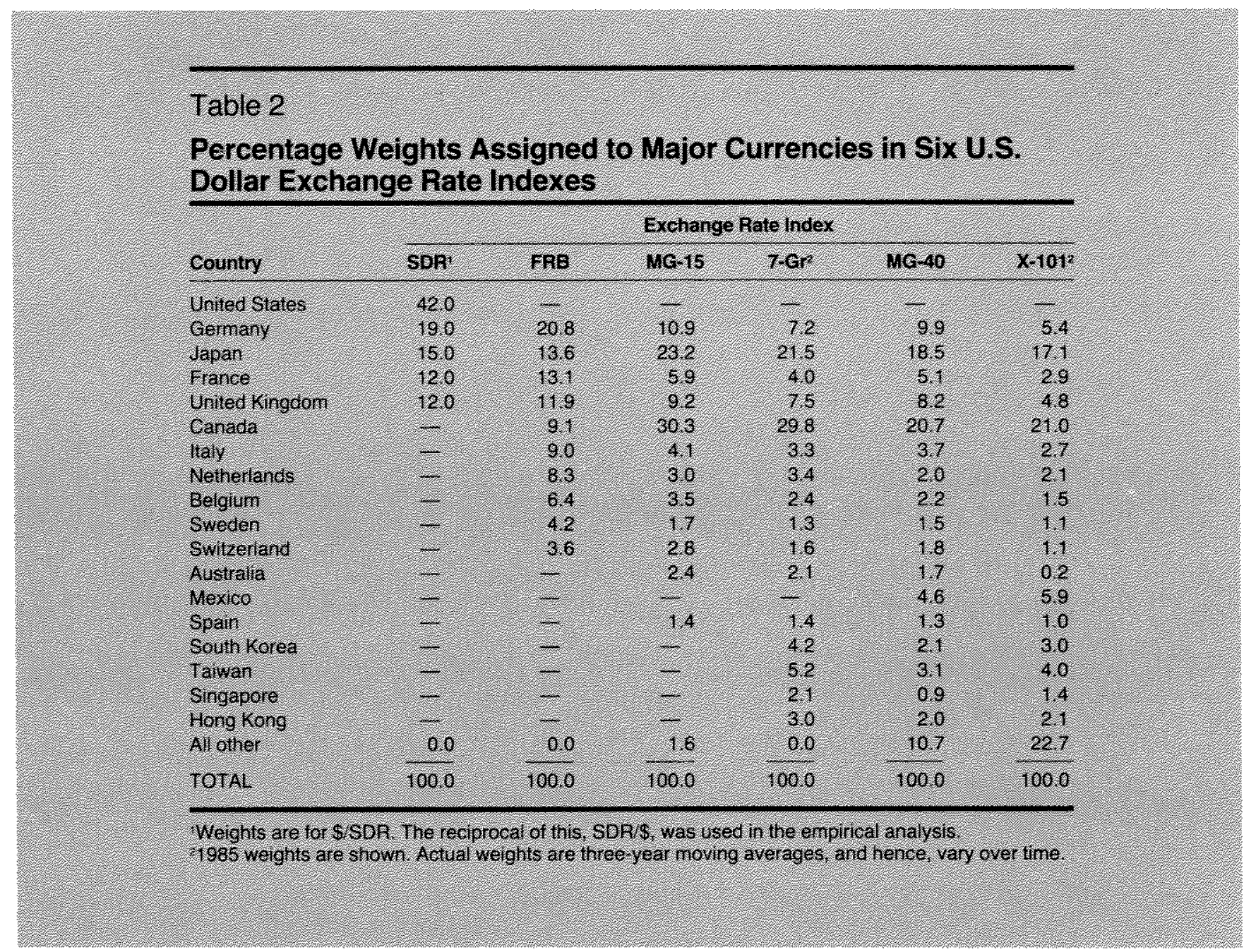

1 and table 3 . Using measures of the real exchange rate, which are the nominal exchange rate indexes adjusted for differences in price levels between the United states and foreign countries, the chart shows that, between 1973 and 1980 , the real value of the dollar fell by as little as 3 percent based on the $\mathrm{MG}-15$ measure, or by as much as 14 percent based on the FRB measure. Similarly, the chart indicates that the real value of the dollar rose by as much as 57 percent (FRB) or as little as 32 percent (MG-15) between 1980

iA geometric, real trade-weighted exchange rate index can be constructed by the formula:

$$
100 \prod_{i=1}^{n} \frac{\left(P_{u s, t}\right.}{P_{i, t}} \cdot \frac{\left.E_{i, t}\right) w_{i}}{E_{t, 0}}
$$

where $P_{\text {us }}$ and $P_{\text {ine }}$ are the price levels in the U.S. and the foreign country, respectively, $E_{i}$ is the nominal exchange rate in foreign currency units per dollar, $f$ denotes time period with base period at zero, $n$ denotes number of currencies in the index and $w_{i}$ is the weight associated with trade between the United States and foreign country i. and 1984. Finally, the range of values for the dollar's decline since the September 1985 Plaza Accord is between -15 percent (SDR) and -22 percent (FRB).

The divergen behavior of these indexes also is evident in table 3 . As the top portion of the table indicates, the SDR index has the smallest average quarterly change, the smallest standard deviation, and narrowest range for quarterly changes; these statistics indicate its relative stability over time. The FRB and MG-15 indexes have slightly wider ranges for quarterly changes over time. The bottom portion of the table, which reports simple correlation coefficients between different pairs of real exchange rates, shows that percentage changes in each index are quite highly correlated. ${ }^{10}$ Overall, the data in chart 1 and table 3 indicate that, although movements in the indexes are

\footnotetext{
${ }^{10}$ Each correlation coefficient is significant at the 0.001 level or higher. Percentage changes in variables are used to eliminate the effects of any common trend in the data.
} 
Chart 1

\section{Selected Real Effective Exchange Rates Expressed as Value of Dollar}

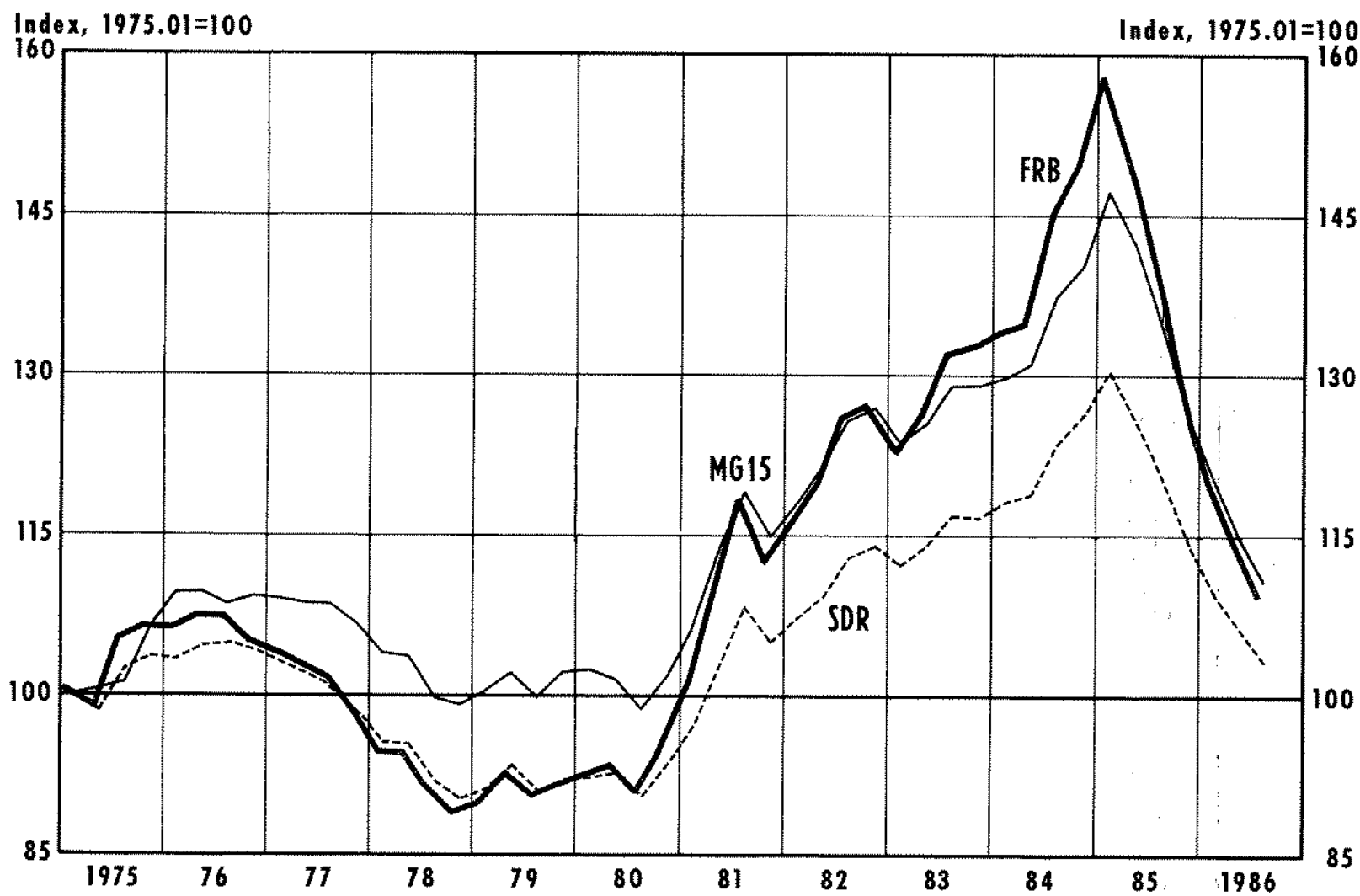

positively correlated, there are substantial quantitative differences in their movements over time.

\section{The New Indexes}

Some economists have viewed these three traditional indexes as deficient not only because they have failed to produce a consensus about the dollar's "true" value, but because they have significant problems of erfor by omission. The primary criticism is that these indexes ignore the importance of LDCs and NewlyIndustrialized Countries (NICs), especially Pacific-rim countries, to U.S. trade. Thus, although the degree of broader coverage differs, the new indexes expand considerably the number of countries represented relative to the more traditional measures.

The countries and weights used to construct the new exchange rate indexes are shown in the last three columns of table 2. Again, refer to table 1 for the characteristics of these indexes. Two of the indexes (MG-40 and 7 -Gr) expand the number of countries primarily to emphasize trade with Pacific-rim coun. tries. The X-101 index covers U.S. trade with all countries for which data are avallable. (There actually is a broader nominal index, based on 131 countries, but gaps in the data on foreign price levels narrow the coverage for the real index.) These newer indexes, because they recognize the increasing importance of U.S, trade with LDCs and NICs over time, are intuitively appealing; it would seem that they should provide a more accurate assessment of the dollar's value.

As a first comparison, chart 2 and table 3 can be examined to investigate relationships between the new and the old indexes. In the table's upper half, percentage changes in each of the new indexes appear to be less variable than the traditional indexes. In the table's lower portion, however, perceftage changes in the new indexes are shown to be significantly correlated with each other and the traditional indexes. Thus, the new indexes appear to reflect much of the information contained in the narrower, traditional 


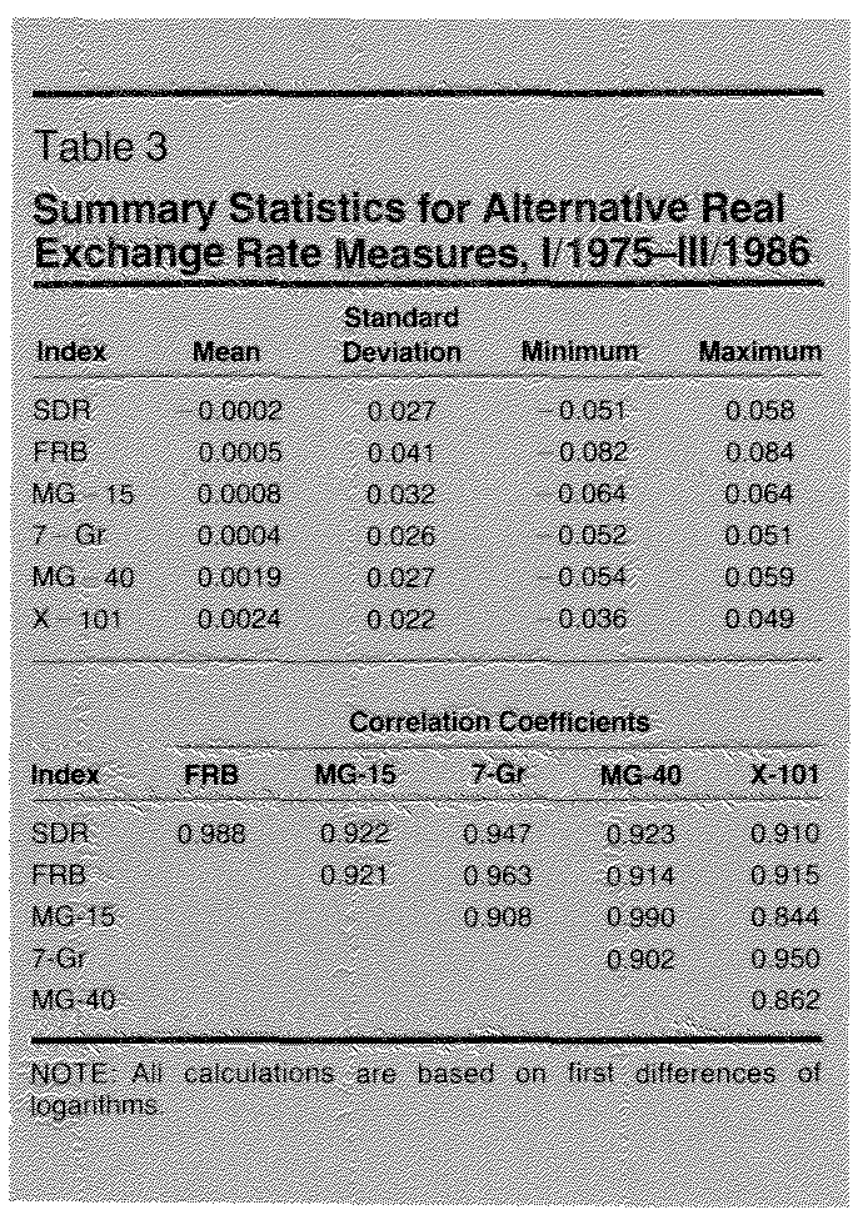

indexes and vice versa. Chart 2 , however, which shows the SDR index plotted against the three new indexes, however, indicates that judgments about how much the dollar's value has changed still depend crucialy on the measure chosen.

\section{THE SENSITVITV OF THADE FLOWS TO GTANGES IN EXCHANG PATES AND INCOME}

The dollar has been deprectating since February 1985. One major puzale that has accompanied this decline is why the trade and curent account balances have not responded more. When analyzed in nominal terms, the standard $I$-curve phenomenon typically is used to explain the slow adjustment of the current accoun balance to a change in the foreign currency value of the dollar. For exaniple, because of prior commitments and contracts. import prices will rise and export prices will tall before the volume of exports and imports responds to a decline in the foreign exchange value of the dollar. When analyzed in real lems, however, only the volume adjustment is rele- vant. Thus, one would expect that lagged adjustment exists and that differentials in real income growth play important roles.

To investigate the sensitivity of real trade flows to changes in real incomes and the real exchange rate, simple reduced-form models were constructed for U.S real exports and U.S. real non-petroleum imports." Before presenting the models, three caveats must be recognized. First, these are highly simplited, aggregated models and are not meant to capture all the specifics and nuances of trade flows. Their sole purpose is to provide a general, quantitative indication of the income and exchange rate elasticities of trade flows to mable a comparison of the various exchange rate indexes. Sccond, because these models are highly aggregated, they ignore the special problems of LDCs and their efforts to generate increased trade surpluses to better service their external debt. Third, all of the statistical results presented are specific to the models estimated and may vary if alternative models or sample periods are applied to the problem. As the references in footnote 1.1 suggest, however, the models estimated certainly follow an established tradition in the empirical literature.

\section{The Export Model}

The model of U.S. real exports emphasizes the forces that affect the world demand for and the US. supply of U.S. exports. The world demand for U.S. exports is assumed to depend on two factors: the level of foreign real economic activity incomel and the price of U.S. goods relative to those of other countries. The higher the level of foreign real income, ceteris paribus, the larger the foreign demand for U.S exports. The higher the price of U.S. goods relative to those abroad, ceteris paribus, the lower the demand for U.S. exports.

The supply of U.S. exports is expressed as a function of the price of U.S. exports relative to the prices of other goods and senices produced in the United States and the utilization of productive capacity in the United States. The higher the price of U.S. exports relative to the prices of other goods or the higher the level of capacity utilization, ceteris paribus, the larger the production of U.S. goods for export.

To generate an estimating equation, a dynamic representation is assumed. Because the demand for or

"These models are fashoned after those of Batten and Belongia (1986), Clark (1974), Goldstein and Khan (1978), and Spitaller (1980). 
Chort 2

\section{Selected Real Effective Exchange Rates Expressed as Value of Dollar}

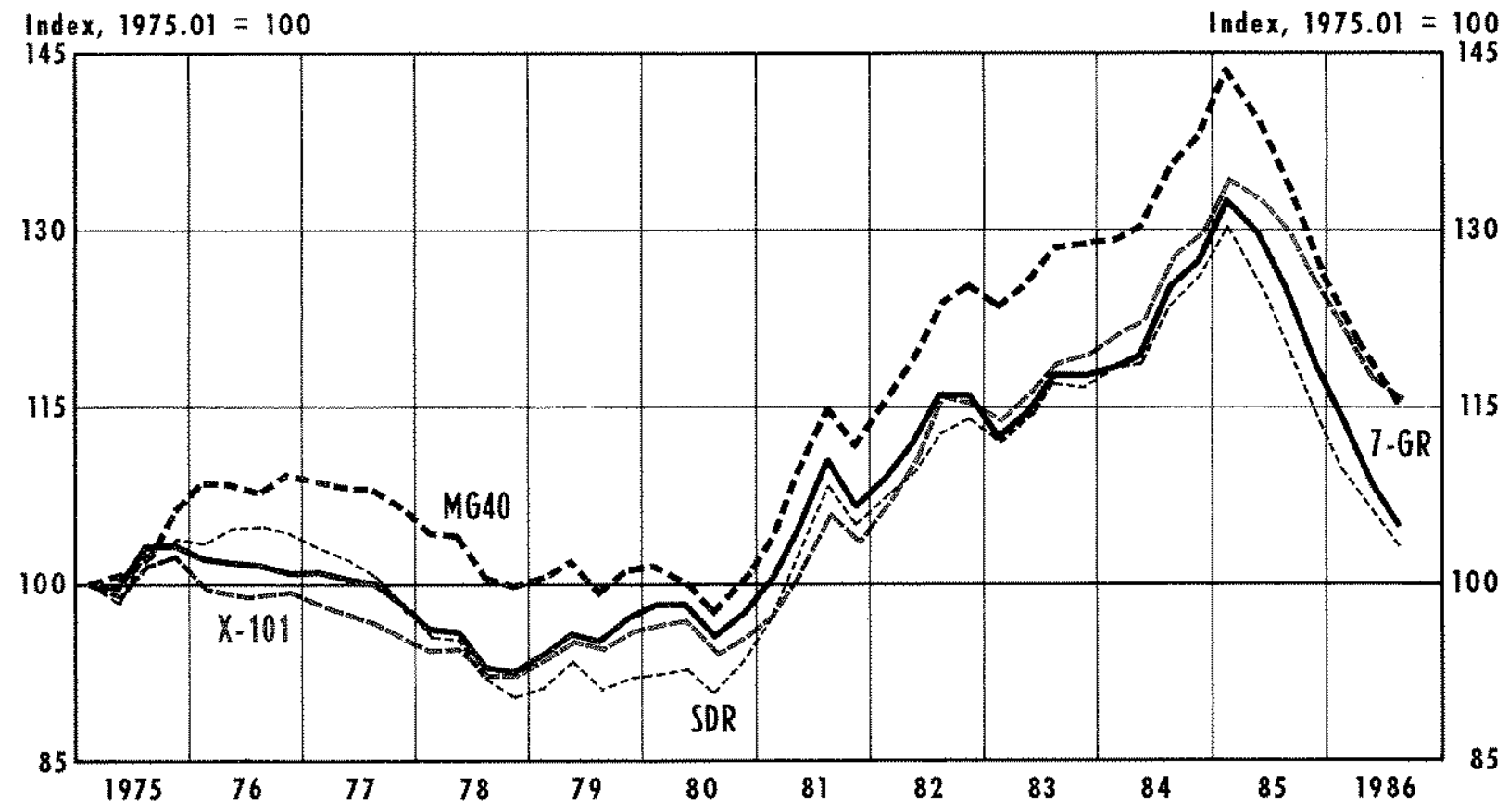

the supply of exports may not adjust instantaneously to changes in the explanatory variables, each explanatory variable is expressed as a distributed lag. Then, a market equilibrium was assumed and a reduced form was obtained; this reduced form is expressed in general terms as:

(1) $\ln \mathrm{EX}_{\mathrm{s}}=\alpha+\frac{\mathrm{p}}{\Sigma} \quad \beta_{i} \ln \mathrm{FGNP}_{t-\mathrm{i}}$

$$
\begin{aligned}
& +\sum_{j=1}^{q} \gamma_{i} \ln (\text { USXP/GNPDEF })_{1-j} \\
& +\sum_{k=1}^{r} \delta_{k} \ln \operatorname{RER}_{1-\mathrm{k}}+\sum_{m=0} \theta_{m} \ln \mathrm{CAP}_{\mathrm{i}-\mathrm{m}}+\varepsilon_{\mathrm{i}},
\end{aligned}
$$

where:

$$
\begin{array}{ll}
\text { EX } & =\text { U.S. real exports, } \\
\text { FGNP } & =\text { index of foreign real GNP, } \\
\text { USXP } & =\text { U.S. export unil value index, }
\end{array}
$$

GNPDEF = U.S. GNP deflator,

RER = real trade-weighted exchange rate (foreign curtency/s), and

CAP = rate of U.S. capacity utilization. ${ }^{22}$

The real exchange rate was included to measure U.S. prices relative to those in the rest of the world (expressed in dollars), taking into account price-level differences across countries.

Results from least squares estimation of equation 1 over the period $1 / 1975$ to II/1986 using each of the six exchange rate indexes are given in table $4 .{ }^{13}$ Each set of results differs only by the real exchange rate measure used in the estimation. The regression results in table 4 indicate how well the altemative real exchange rate indexes explain movements in real U.S. exports.

\footnotetext{
12Lag lengths were selected using techniques presented in Batten and Thornton (1984).

"The sample period actually begins in $1 / 1973$; eight observations are lost in the lag-length selection process.
} 


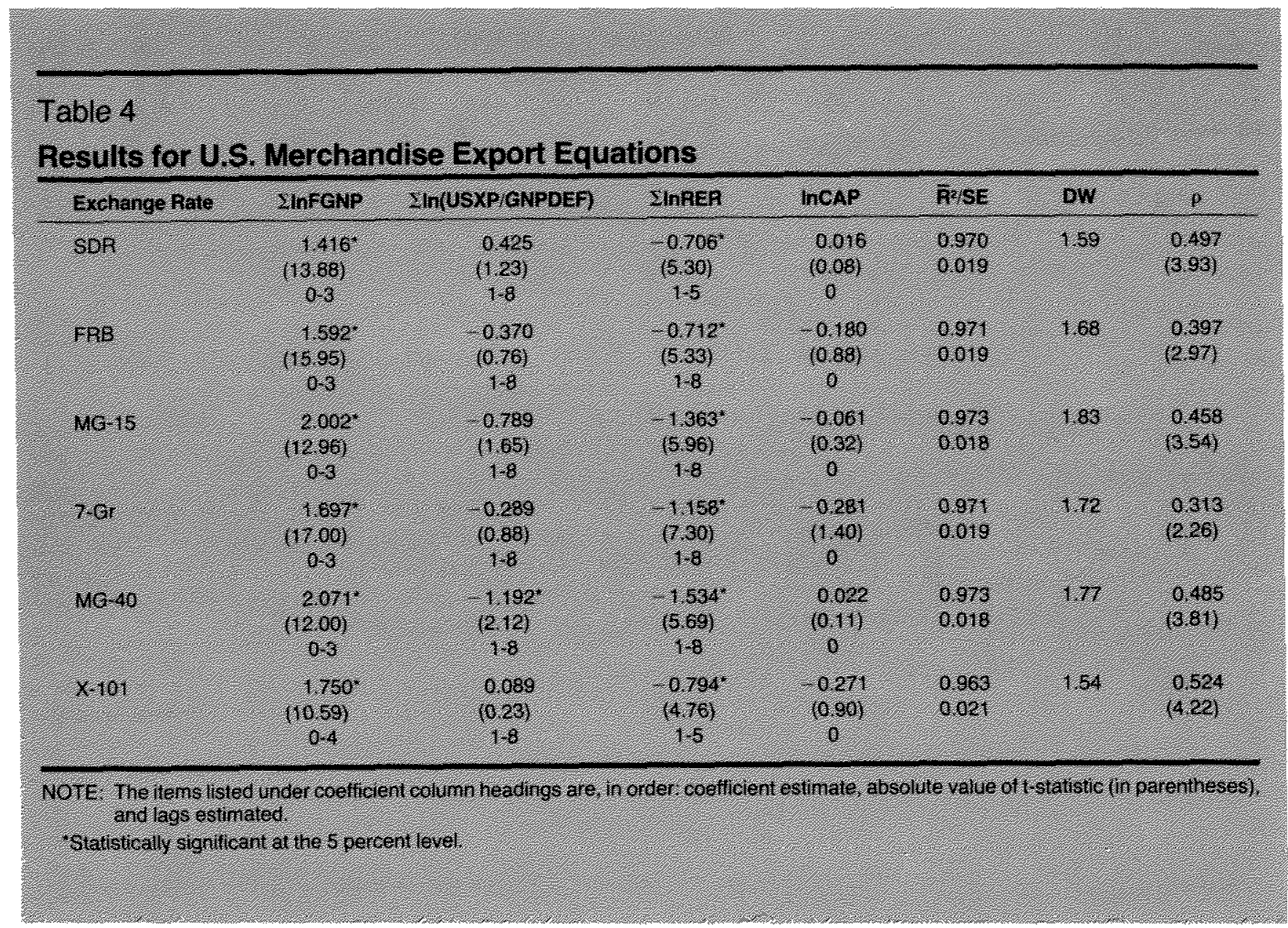

On the basis of the summary statistics and estimated coefficients, table 4 offers little guidance in distinguishing the perfomance of one index from another. The equations display roughly similar explanatory power (based on $\widetilde{R}^{2}$ and standard error) and all exhibit positive first-order autocorrelation. ${ }^{34}$ The estimated income and price (exchange rate) elasticities are statistically significant, and their signs meet $e x$ ante expectations. In general, the estimated coefficients of the supply-side variables (relative export prices and the rate of capacity utilization) are not statistically significant.

There are some marked differences, however, in the magnitude and timing of the response of real U.S. exports to changes in the real trade-weighted value of the dollar. Depending upon the exchange rate index

${ }^{4}$ Correcting for first-order autocorrelation had virtually no effect on the parameter estimates. Also, including a lagged dependent variable on the right-hand side of the equation appeared to "correct" the autocorrelation without affecting the estimated paramelers. Furthermore, all statistically significant coefficients of the lagged dependent variable were significantly less than one. chosen, this response takes place over a range of five to eight quarters. Moreover, export demand can be said to be inelastic (FRB and SDR), unit-elastic (MG-15, X101 and 7 -Gr) or elastic $(\mathrm{MG}-40)^{15}$ Because policymakers are chiefly interested in how much and how quickly U.S. exports respond to a change in the dollar's value, the wide qualitative and quantitative diversity among the estimated coefficients in table 4 is troublesome.

\section{The Import Model}

A similar generic model was constructed for U.S. real non-petroleum imports. U.S. demand for foreignproduced goods was assumed to be a function of U.S. real income and the relative price of U.S. goods to foreign-produced goods. The foreign supply of imports was assumed to be a function of the price of

${ }^{15}$ This, of course, is based on testing the null hypothesis that

$$
\sum_{k=1}^{r} \delta_{k}=1
$$




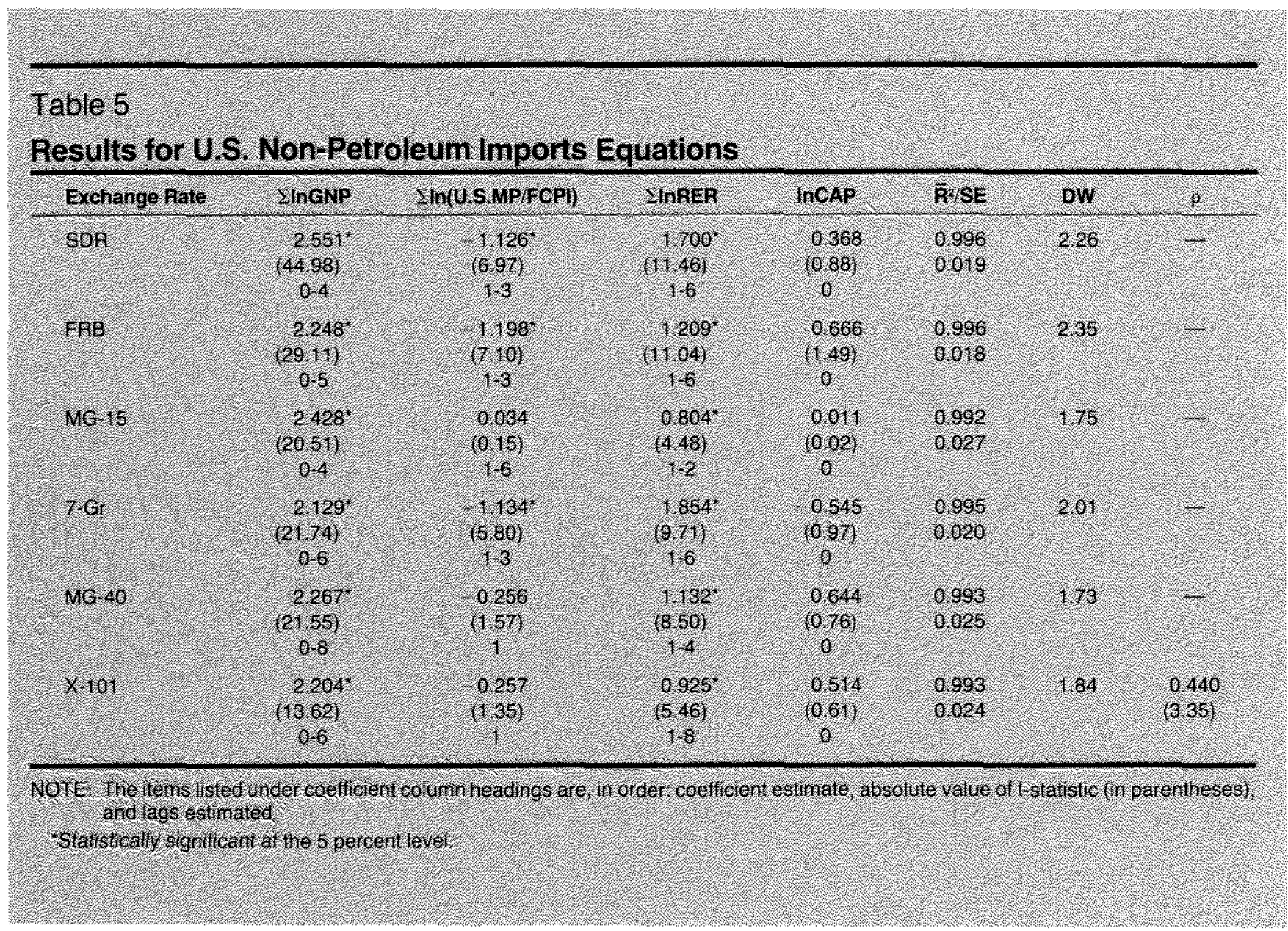

imports relative to the foreign general price level and the utilization of productive capacity abroad. The real exchange rate again was used as the measure of U.S. prices relative to those abroad. In the import model, however, changes in the real exchange rate should have a positive impact. That is, a rise in the real exchange rate indicates that U.S. prices are rising relative to those abroad; hence, U.S. consumers should substitute relatively more foreign-produced for U.S.produced goods.

Generating a reduced-form estimating equation in the same manner as before yields:

$$
\text { (2) } \begin{aligned}
\ln \mathrm{EM}_{1} & =\alpha+\sum_{\mathrm{i}=0}^{\mathrm{p}} \beta_{\mathrm{i}} \ln \mathrm{GNP}_{\mathrm{i}-\mathrm{i}}
\end{aligned}
$$

where:

$$
\begin{aligned}
& \mathrm{IM}=\text { U.S. real non-petroleum imports, } \\
& \mathrm{GNP}=\text { U.S. real GNP. }
\end{aligned}
$$

USMP = U.S. non petroleum import tunit value index,

FCPI = index of foreign CPI, and

$\mathrm{FCAP}=$ rate of foreign capacity utilization.

The results from estimating this equation for each exchange rate index, with appropriate lag length selections, are reported in table 5 . Once again, the equathons differ little on the basis of the summary statistics and estimated coefficients. Also once again, the estimated exchange rate effects on U.S. imports vary widely: the adjustment lag varies from two to eight quarter's and import demand is either unit-elastic (FRB, MG-15, X-101 and $\mathrm{MG}-40$ ) or elastic (SDR and 7Gr) depending on the specific index. The results in tables 4 and 5 indicate that changes in the dollar's real value affect the U.S. merchandise trade deficit; the estimated magnitude and timing of the effests, how ever, differ substantially across the exchange rate indexes examined. ${ }^{\text {ti }}$

${ }^{16} \mathrm{An}$ investigation of the last eight in-sample errors for each equation, however, reveals that most lie within one standard error of zero. Hence, the in-sample results do not indicate that any exchange rate index outperforms any other one. 


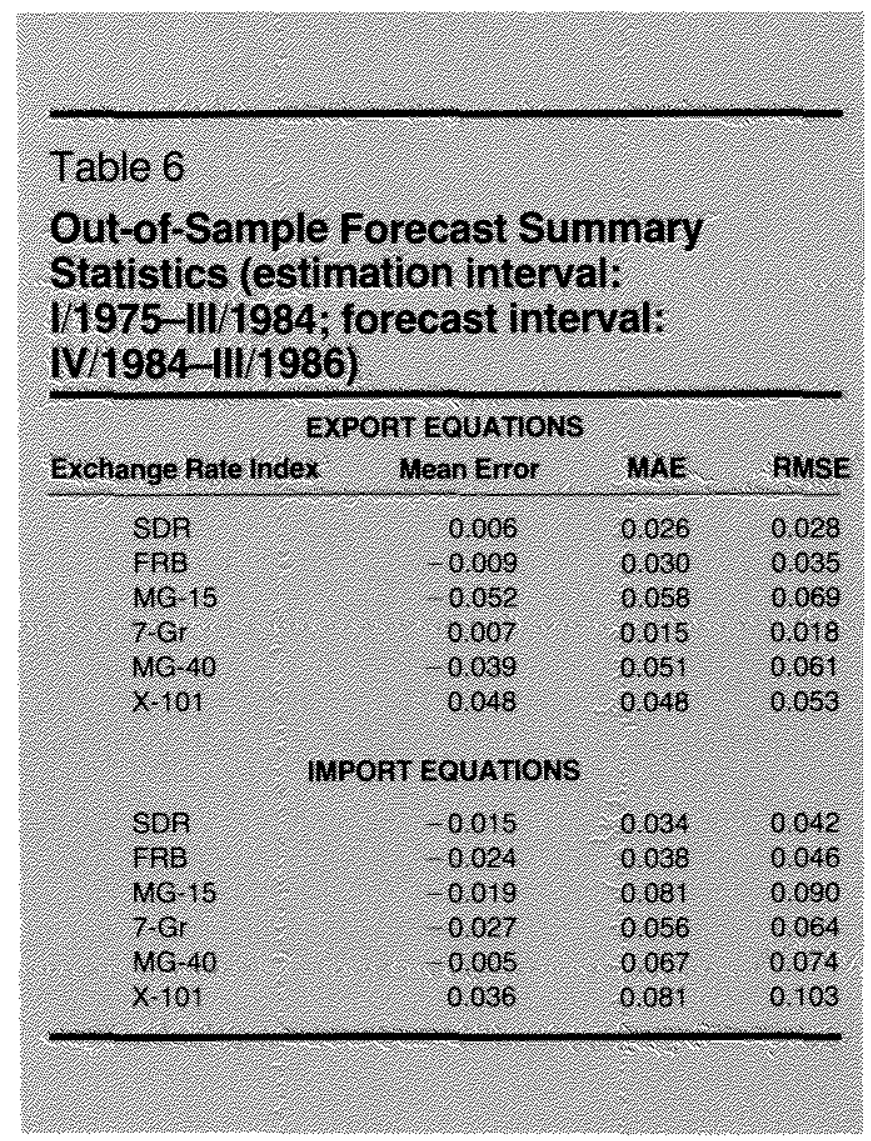

Because we do not know the actual exchange rate elasticities for exports and imports or the correct adjustment lag, ex ante, our only guide in choosing an exchange rate index is its empirical performance. The results, however, suggest that there was no notably superior index. Thus, the new indexes do not appear to add much, if anything, to our knowledge about the response of trade flows to changes in the exchange rate. ${ }^{\text {t? }}$

\section{OUT-OP-SAMPLE FOPECABT ERPOPS}

An alternative criterion for choosing among alternative exchange rate indexes is their relative performance in predicting trade flows beyond the range of data used to estimate the coefficients for equations 1 and 2 . This out-of-sample predictive criterion emphasizes another practical application of an exchange rate index: if the actual path followed by the dollar's value

${ }^{17}$ Testing for the temporal stability of the estimated exchange rate elasticity for the various indexes during the floating exchange rate period may indicate the superiority of one of more indexes over the others. Given the lack of parsimony in the parameterization of the estimated equations and the relatively short sample period, how. ever, this investigation could not be performed here. had been known in advance, how well could changes in export and import flows have been predicted? To examine this issue, equations 1 and 2 were re estimated for the I/1975-IIL/1984 period, and out-ofsample errors were calculated for exports and imports for the eight quarters between $\mathrm{W} / 1984$ and IIV/1986. Summary statistics for these out-of-sample predictive errofs are reported in table 6 ; the errors are plotted in charts 3 and 4 .

The table reports the mean error, the mean absolute error (MAE) and the root-mean-squared error (RMSE). For the U.S. export equations in the table's upper half, the $7+\mathrm{GF}$ index had the lowest MAE and RMSE values and the second-smallest mean error. Performing nearly as well were the FRB and SDR indexes. In contrast, out-of-sample predictions using the X-101 and $M G-40$ indexes, which were designed to give broader coverage to trade flows, show larger errors.

A look at the individual export forecast errors in chart 3 allows several interesting comparisons. First, the performances of the FRB, SDR and 7-Gr indexes are noticeably and consistently better than those of the other three indexes. Second, the relatively poor performance of the X-101 index stands out clearly: it consistently underpredicts exports

The two Morgan Guaranty indexes also perform relatively poorly, generaly overpredicting exports. Surprisingly, however, the broader Morgan index (MG40) performs just about as badly as the narrow Morgan index (MG-15). If broader indexes genuinely tepresent more accurate measures of the foreign exchange value of the dollar, the MG-40 should have outpertormed the MG-15. Moreover, the FRB index, whose coverage is similar to the MG-15, outpeformed both Morgan indexes. ${ }^{\text {sh }}$

The out-of-sample error statistics for the U.S. nonpetroleum import equations tell a similat story. 'The narrow SDR and FRB indexes have the smallest MAE and RMSE values, while error statistics for the broader $X-101$ and $M G-40$ indexes are several times larger. In fact, as table 6 indicates, the $\mathrm{X}-101$ index, which has the broadest coverage of trade flows, generally has the worst forecasting performance for the indexes examined. Conversely, the narrowest index, the $\mathrm{SDR}$, has the best emor statisties for imports and second-best

\footnotetext{
19 Since the FRB and MG-15 indexes differ primarily in the use of multilateral (FRB) vs. bilateral (MG-15) weights, it may be that the weighting scheme used is more important than the countries included in the index. The use of different price indexes to deflate the FRB and MG-15, however, may also affect the results.
} 
Chant 3

\section{Out-of-Sample Errors for Export Equations}

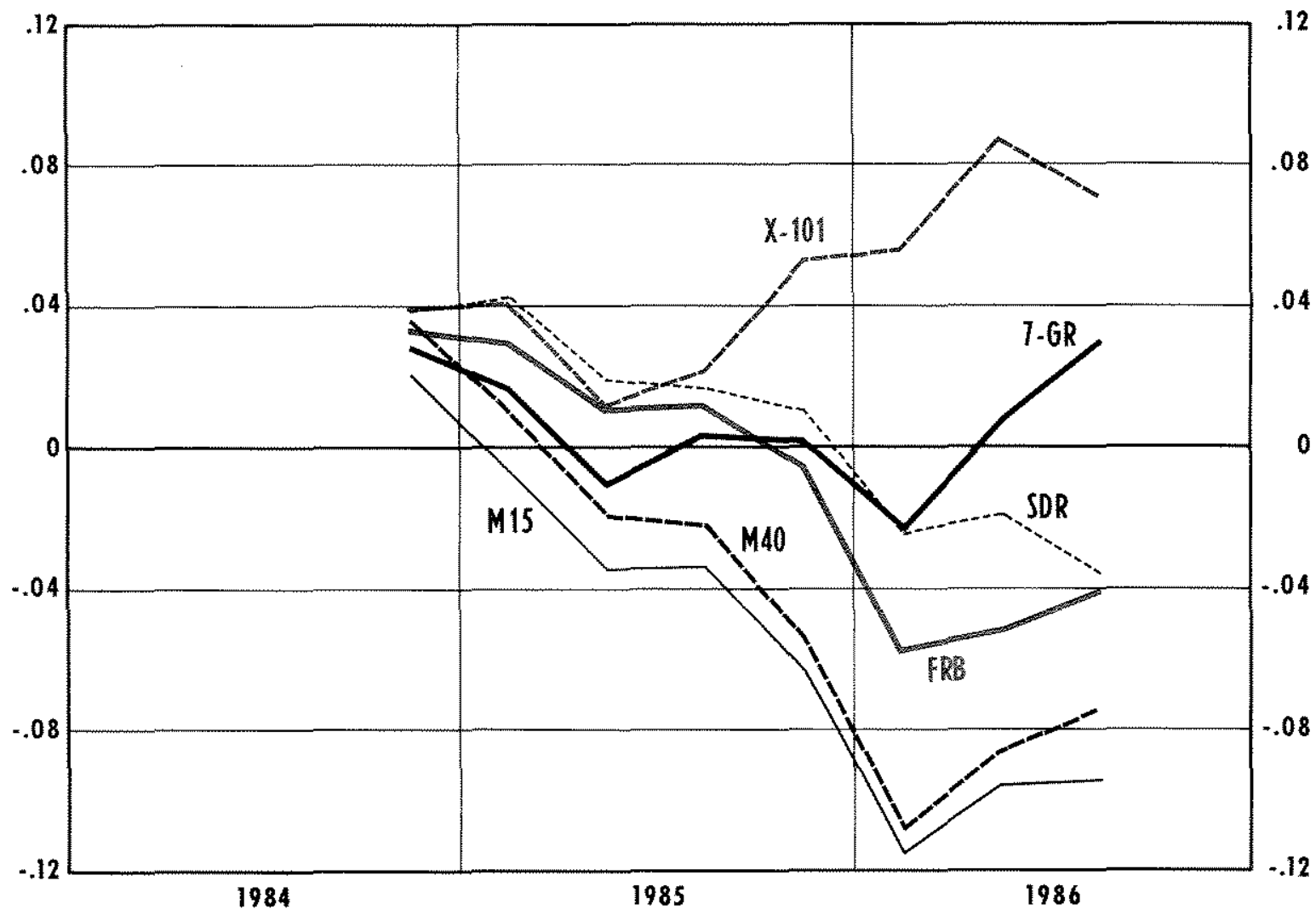

for exports. Error statistics for the 7-Gr and FRB indexes are only slightly worse than those for the SDR.

The individual import forecast errors in chart 4 , while less disparate than those of the export equations, offer similar comparisons. Although all exchange rate indexes underpredict imports by the end of the forecast period, the FRB and SDR indexes generally exhibit the best performances; the performance of the $X-101$ index is generally the worst, with the two Morgan indexes and the $7-\mathrm{Gr}$ somewhere in between.

Overall, the out-of-sample results in table 6 and charts 3 and 4 provide no support for the notion that increasing the number of currencies in an exchange rate index improves its out-of-sample forecasts of trade flows. If anything, the results here suggest that the narrow indexes perform marginally better. ${ }^{19}$

\footnotetext{
19lt is possible that including more currencies in an index adds noise to the measure from superfluous currency movements largely unrelated to trade.
}

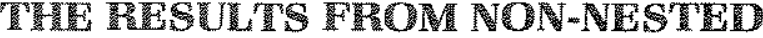 ThSTS}

The fundamental question is whether the new indexes contain more (or better) information about the impact of changes in the dollar's value on trade flows. If the trade equations specified for the old and new indexes were nested, testing whether the new indexes add significantly to the information of the old indexes would be a straightforward operation. ${ }^{20}$ The specified relationships between exports and imports and various measures of the exchange rate, however, are not nested and require an alternative approach to hypothesis testing.

The test employed to investigate whether the new indexes add significantly to the information in the old

${ }^{20} \mathrm{~A}$ nested test is one in which all of the information contained in the null hypothesis is also contained in the altemative. For example, the standard t-test that an estimated coefficient is statisticaliy different from zero is a nested test. 
Chart 4

\section{Out-of-Sample Errors for Import Equations}

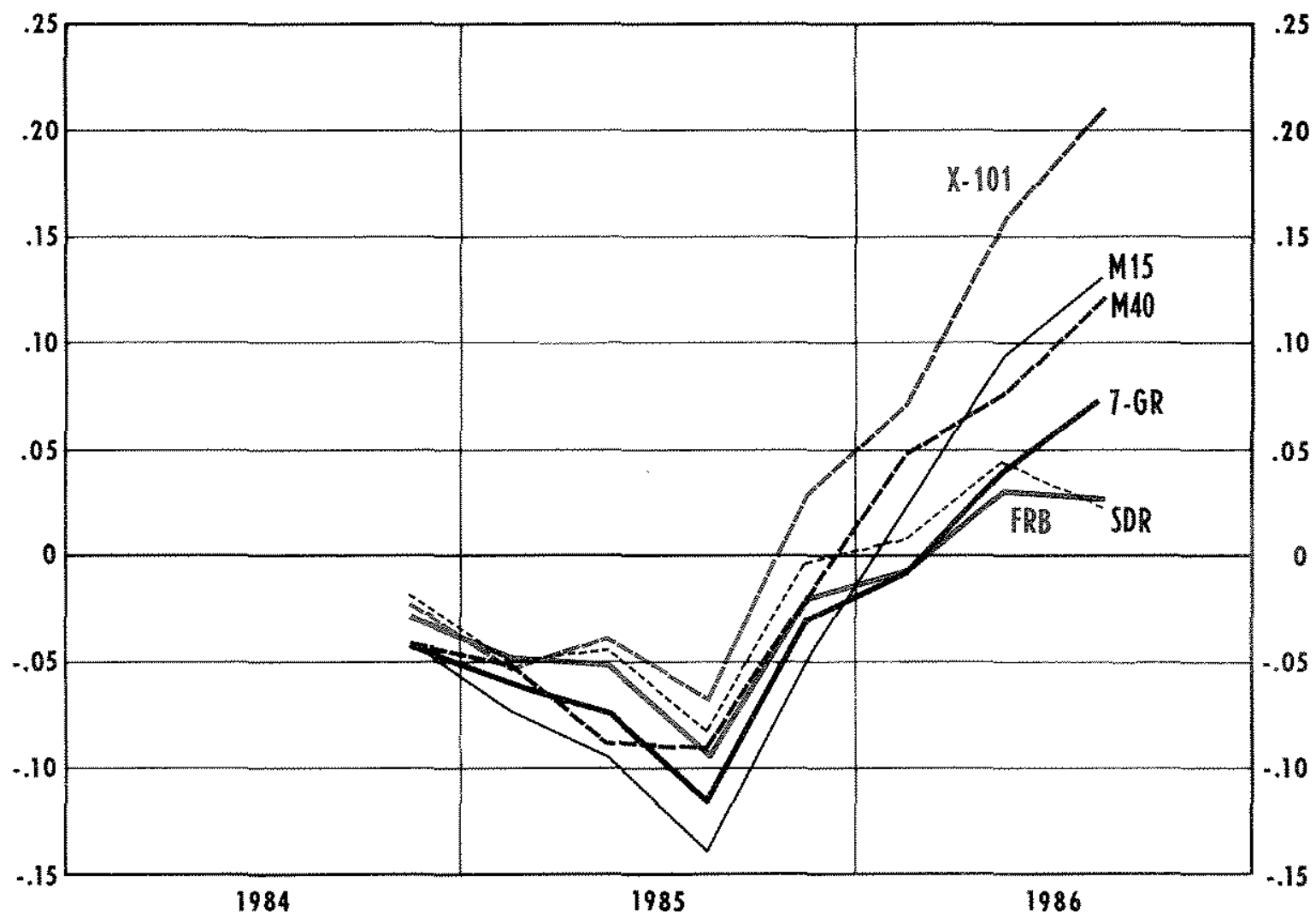

indexes is the $J$-test. ${ }^{21}$ One specification of the trade equation is hypothesized to be true and a second specification, using a different exchange rate measure, is hypothesized as the alternative specification. The $\mathbf{j}$ test requires estimating the altemative specification and generating a vector of fitted values for the dependent variable (exports or imports). The specification proposed under the null hypothesis is then estimated with this vector of fitted values from the alternative

21See Davidson and Mackinnon (1981). The J-test establishes one specification as the null hypothesis, then tests whether an alternative specification adds to the explanatory power of the specification under the null hypothesis. For example, assume that we want to test the specification,

$$
H_{0}: y=f(x, z)+\varepsilon_{3}
$$

against the alternative,

$$
H_{1}: y=g(w, z)+\varepsilon_{\tilde{z}} \text {. }
$$

The $\mathrm{J}$-test is conducted simply by estimating

$$
y=(1-\phi) f(x, z)+\phi \hat{g}+\varepsilon \text {, }
$$

where $\hat{g}$ is the vector of predicted y under the atternative hypothesis, and testing whether $\phi$ is significantly different from zero using a specification as an additional explanatory variable. If the alternative measure of the exchange rate adds explanatory power to the specification containing the hypothesized "true" measure, the estimated coefficient of the vector of predicted values will be significantly different from zero. The conclusion drawn from this result is that the specification with the altemative exchange rate index is preferred to that with the hypothesized true index. To complete the test the hypothesized true (null) and altemative indexes are reversed and the same procedure is repeated. The initially specified alternative can be preferred to the null only if the null specification does not add explanatory power to the alternative in the second stage of the test. If the null does add explanatory power in the second stage, then the test does not allow the choice of one specification over the other.

conventional t-test. If the data are better fit to $f(x, z)$, then $\phi$ should not be different from zero. Alternatively, if $\phi$ is different from zero, then $g(w, z)$ adds to the explanatory power of $f(x, z)$. To complete the test, the process is repeated by reversing the null and alternative hypotheses and repeating the same testing procedure. 
Table 7

\section{J-Test Results for Export Equations}

\begin{tabular}{ccccccc}
\hline \multirow{2}{*}{$\begin{array}{c}\text { Exchange Rate Index } \\
\text { Under Null Hypothesis }\end{array}$} & \multicolumn{6}{c}{ Exchange Rate Index Under Alternative Hypothesis } \\
\cline { 2 - 7 } & SDR & FRB & MG-15 & $\mathbf{7 - G r}$ & MG-40 & X-101 \\
\hline SDR & - & $3.63^{*}$ & $4.46^{*}$ & $3.76^{*}$ & $4.29^{*}$ & $2.15^{*}$ \\
FRB & $2.14^{*}$ & - & $3.09^{*}$ & 1.37 & $3.00^{*}$ & 1.20 \\
MG-15 & 1.51 & 1.72 & - & $1.99^{*}$ & 1.77 & $2.49^{*}$ \\
$7-G r$ & $2.14^{*}$ & 1.27 & $3.19^{*}$ & - & $3.09^{*}$ & 0.97 \\
MG-40 & 1.75 & 1.91 & 1.75 & $2.10^{*}$ & - & $2.61^{*}$ \\
X-101 & $4.35^{*}$ & $4.20^{*}$ & $5.85^{*}$ & $4.04^{*}$ & $5.56^{*}$ & - \\
\hline
\end{tabular}

Statistically significant at the 5 percent level.

\section{Table 8}

\section{J-Test Results for Import Equations}

\begin{tabular}{|c|c|c|c|c|c|c|}
\hline \multirow{2}{*}{$\begin{array}{l}\text { Exchange Rate Index } \\
\text { Under Null Hypothesis }\end{array}$} & \multicolumn{6}{|c|}{ Exchange Rate Index Under Alternative Hypothesis } \\
\hline & SDR & $\mathrm{FRB}$ & MG-15 & $7-\mathrm{Gr}$ & $M G-40$ & $x-101$ \\
\hline $\mathrm{SDR}$ & - & $7.18^{\star}$ & $3.01^{*}$ & $6.98^{\star}$ & $3.93^{*}$ & $5.95^{\star}$ \\
\hline $\mathrm{FRB}$ & 0.42 & - & -0.32 & 0.95 & 0.27 & 1.11 \\
\hline$M G-15$ & 1.23 & $6.23^{\star}$ & - & $5.66^{*}$ & $3.11^{*}$ & $4.66^{*}$ \\
\hline $7-\mathrm{Gr}$ & $2.12^{\star}$ & $2.70^{*}$ & 1.57 & - & 1.16 & 0.71 \\
\hline$M G-40$ & 1.87 & $5.78^{\star}$ & $2.40^{\circ}$ & $4.83^{+}$ & - & $3.85^{*}$ \\
\hline$x-101$ & $2.80^{*}$ & $5.81^{*}$ & $2.61^{*}$ & $4.39^{\prime}$ & $2.44^{*}$ & - \\
\hline
\end{tabular}

* Statistically significant at the 5 percent level.

Tables 7 and 8 present t-statistics for the J-tests conducted. The left-hand columns of the tables list the exchange rate indexes hypothesized as "true" under the null hypothesis. The other columns show tstatistics, which indicate whether the specification with an alternative exchange rate index adrds significant information to the specification employing the index in the left-hand column.

Tle; iesults in table 7 for the export cquations arc ambiguous in the sense that no index or set of indexes clearly dominates the others. Of the $30 \mathrm{t}$-statistics reported, 20 are significant and four more are nearly significant at the 5 percent level. Moreover, there are no consistent patterns in the t-statistics. For example, each alternative index adds significantly to the information in the SDR index but the SDR index adds only to three of the five altematives. Each alternative index similarly adds to the X-101 index and the X-101 adds only to three of the remaining five. In contrast to the SDR results, however, the three indexes to which the $\mathrm{X}-101$ adds information are not the same three to which the SDR index adds information. The remaining results in table 7 also lack the transitivity that would permit drawing any conclusions about a dominant index or set of indexes with greater information content.

The results for the import equations in table 8 , however, yield clearer conclusions. The FRB index adds to the information of all other indexes in the import equation, while none of the other indexes adds to the information in the FRB measure. On this J-test criterion, the $7-\mathrm{Gr}^{\mathrm{r}}$ index has the second-best pertor- 
mance, with only two indexes (FRR and SnR) adding to its information and the 7-Gr adding to the information of all measures but the FRB index. Consistent with earlier results, the two indexes with the broadest coverage of currencies, the X-101 and MG-40, are dominated by the other indexes: all five indexes add to the information of the X-101 and four of five contribute to the MG-40. Consequently, the answer to the simple question, "Does greater coverage of currencies, per se, add to the information content of an exchange rate indox?" is cloarly no.

\section{CONCLUSIONS}

Several new indexes of the dollar exchange rate have been developed in the past year. The justification for their construction was that the distribution of U.S. trade flows had changed dramatically since the 1970s and, for that reason, existing exchange rate indexes, based on trade with industrialized countries, did not reflect the recent increased importance of trade with LDCs and Pacific-rim countries.

The key test of an exchange rate index, however, is not its intuitive justification but its practical utility. A consistent set of tests applied to the major existing indexes indicated that the new broader measures performed no better than the old measures. In fact, on the basis of forecasting performance, they performed worse than the cxisting, morc narrowly based $c x$. change rate indexes. Additional tests, which examined the marginal information content of the new indexes, also found a traditional, narrow measure of the dollar's value to dominate the newer indexes. Hence, the new exchange rate indexes do not appear to provide better answers to old questions about trade flows.

\section{REFERENCES}

Bank of Japan, Research and Statistics Department. "On Effective U.S. Dollar Exchange Rate Indices," Special Paper No. 147 (December 1986).

Batten, Dalias S., and Michael T. Belongia. "The Recent Decline in Agricultural Exports: Is the Exchange Rate the Culprit?" this Review (October 1984), pp. 5-14.

Batten, Dallas S., and Daniel L. Thornton. "How Robust Are the Policy Conclusions of the St. Louis Equation?: Some Further Evidence," this Review (June/July 1984), pp. 26-32.

Belongia, Michael T. "Estimating Exchange Rate Effects on Exports: A Cautionary Note," this Review (January 1986), pp. ১-16.

Clark, Peter B. "The Effects of Recent Exchange Rate Changes on the U.S. Trade Balances," in Peter B. Clark, Dennis E. Logue and Richard J. Sweeney, eds., The Effects of Exchange Rate Adjustments, the proceedings of a conference sponsored by OASIA Research (Department of the Treasury, 1974), pp. 20136.

Cox, W. Michael. "A New Alternative Trade-Weighted Dollar Exchange Rate Index," Federal Reserve Bank of Dallas Economic Review (September 1986), pp. 20-28.

Davidson, R., and J. G. MacKinnon. "Several Tests for Model Specification in The Presence of Alternative Hypotheses," Econometrica (May 1981), pp. 781-93.

Dutton, John, and Thomas Grennes. "The Measurement of Effective Exchange Rates Appropriate for Agricultural Trade," Department of Economics and Business. North Carolina State University (November 1985).

Goldstein, Morris, and Mohsin S. Khan. "The Supply and Demand for Exports: A Simultaneous Approach," Review of Economics and Statistics (May 1978), pp. 275-86.

Hervey, Jack L., and William A. Strauss. "The International Value of the Dollar: An Inflation-Adjusted Index," Federal Reserve Bank of Chicago Economic Perspectives (January/February 1987), pp. $17-28$.

Morgan Guaranty Trust Company. "Dollar Index Confusion," World Financial Markets (October/November 1986), pp. 14-19.

Rosensweig, Jeffrey A. "A New Dollar Index: Capturing a More Global Perspective," Federal Reserve Bank of Atlanta Economic Review (June/July 1986), pp. 12-22.

Spitäller, Erich. " "Short-Run Effects of Exchange Rate Changes on Terms of Trade and Trade Balance," IMF Staff Papers (June 1980), pp. $320-48$. 